\title{
Breve Análise Sobre a Natureza e Política: outro mundo possível?
}

\author{
Breve Análisis Sobre la Naturaleza y Política: otro mundo posible?
}

A Brief Analysis of Nature and Politics: another possible world?

\author{
Natália Carolina Oliveira Vaz ${ }^{1}$ \\ Raquel Riffel ${ }^{2}$
}

\begin{abstract}
Resumo
A relação do homem com a natureza é multifacetada, isto é, assim como o homem é dependente do que extrai do meio ambiente, ele também interfere - de forma positiva ou negativa - e altera as condições ambientais ao seu em torno. A partir destas modificações realizadas na natureza pela ação do ser humano, se desenvolvem relações de interdependência social. O homem é um ser social que precisa destas múltiplas relações, mas a relação homem x natureza $\mathrm{x}$ política, pode ser considerada a mais importante delas. Este trinômio demonstra a dependência humana dos recursos que a natureza oferece, para que, com a força de trabalho do ser humano, a primeira natureza seja transformada em segunda. Ao terceiro elemento - a política - concede-se a motricidade pela influência que exerce, isto é, a política desenvolve as diretrizes que promoverão equilíbrio, sustentabilidade e justiça ambiental, ou na ausência destes todos, admitirem-se numa questão da ausência, que haja uma relação consentida pela sociedade. Neste contexto, o presente trabalho apresenta sua argumentação sob os conceitos de justiça e injustiça ambiental. Os resultados obtidos a partir do desenvolvimento deste trabalho apontam para determinados grupos sociais propensos a sofrer com a injustiça ambiental, os quais são, primordialmente, desfavorecidos economicamente. Neste sentido emerge a concepção do "Bem Viver", que surge como uma forma de equilíbrio entre política e meio ambiente, proporcionando meios de reparação para a população exposta a este tipo de injustiça.
\end{abstract}

Palavras-Chave: Ambiente, Sociedade, Política, Injustiça, Justiça.

\section{Resumen}

La relación del hombre con la naturaleza es multifacética, es decir, así como el hombre es dependiente de lo que extrae del medio ambiente, él también interfiere - de forma positiva o negativa - y altera las condiciones ambientales a su alrededor. A partir de estas modificaciones realizadas en la naturaleza por la acción del ser humano, se desarrollan relaciones de interdependencia social. El hombre es un ser social que necesita estas múltiples relaciones, pero la relación hombre x naturaleza x política, puede ser considerada la más importante de ellas. Este trinomio demuestra la dependencia humana de los recursos que la naturaleza ofrece, para que, con la fuerza de trabajo del ser humano, la primera naturaleza sea transformada en segunda. Al tercer elemento -la política-se concede la motricidad por la influencia que ejerce, es decir, la política desarrolla las directrices que promoverán equilibrio, sostenibilidad y justicia ambiental, o en ausencia de todos, admitirse en una cuestión de la ausencia, que haya una relación consentida por la sociedad. En este contexto, el presente trabajo presenta su argumentación bajo los conceptos de justicia e injusticia ambiental. Los resultados obtenidos a partir del desarrollo de este trabajo apuntan a determinados grupos sociales propensos a sufrir con la injusticia ambiental, los cuales son, primordialmente, desfavorecidos económicamente. En este sentido emerge la concepción del "Bien Vivir", que surge como una forma de equilibrio entre política y medio ambiente, proporcionando medios de reparación para la población expuesta a este tipo de injusticia.

\footnotetext{
${ }^{1}$ Doutoranda no Programa de Pós-graduação em Geografia da Universidade Federal do Paraná - UFPR (PR/BRASIL). Participante do Núcleo Paranaense de Pesquisa em Religião (NUPPER). É membro associado da Academia Nacional de Estudos Transnacionais - ANET e da Associação Brasileira de História das Religiões ABHR. E-mail de contato: natihvaz@gmail.com.

${ }^{2}$ Mestranda em Desenvolvimento Regional no Programa de pós Graduação em Desenvolvimento Regional da Fundação Universidade Regional de Blumenau - FURB - (SC/BRASIL). Integrante do Grupo de Pesquisas Ethos, Alteridade e Desenvolvimento - GPEAD/FURB. E-mail: raquel_riffel@ hotmail.com.
} 
Palabras claves: Medio ambiente, Sociedad, Política, Injusticia, Justicia.

\begin{abstract}
The man's relationship with nature is multifaceted, that is, just as man is dependent on what he extracts from the environment, he also interferes - positively or negatively - and changes the environmental conditions around him. From these modifications carried out in nature by the action of the human being, relationships of social interdependence develop. Man is a social being who needs these multiple relationships, but the relation $x$ man $x$ nature $x$ politics, can be considered the most important of them. This trinomial demonstrates the human dependence of the resources that nature offers, so that with the work force of the human being, the first nature is transformed into second. The third element - politics - is granted motricity by the influence it exerts, that is, the policy develops guidelines that promote equilibrium, sustainability and environmental justice, or in the absence of these all, to be admitted in a matter of absence, that there is a relationship allowed by society. In this context, the present paper presents its arguments under the concepts of justice and environmental injustice. The results obtained from the development of this work point to certain social groups prone to suffer from environmental injustice, which are primarily economically disadvantaged. In this sense emerges the concept of "Well Living", which emerges as a way of balancing policy and environment, providing means of reparation for the population exposed to this type of injustice.
\end{abstract}

Keywords: Environment, Society, Politics, Injustice, Justice.

\title{
1. Introdução
}

O ser humano pode ser considerado como parte integrante da natureza, tendo em vista que se trata da única espécie capaz de interferir - positiva ou negativamente - em seu meio ambiente. O homem é um ser social, dotado de múltiplas relações de interdependência, das quais se destacam no presente trabalho o trinômio: homem x natureza x política. $\mathrm{O}$ homem que extrai os recursos naturais necessários para a subsistência e que também produz, cria e recria o ambiente em seu em torno; a natureza, que provém e proporciona a sobrevivência da humanidade e, finalmente, a política que é capaz de promover tanto a justiça ambiental, quanto a injustiça ambiental.

No decorrer deste artigo emerge o debate a respeito da justiça e da injustiça ambiental. O direito a natureza, ao ambiente e a uma vida saudável é um direito universal, mas é sabido que ele não se estende de forma plena a todos os segmentos sociais brasileiros. A poluição, detritos industriais, contaminação da água potável, são reflexos do modelo econômico atual, que impacta a natureza como um todo, mas que reflete com maior intensidade às pessoas socioeconomicamente desfavorecidas, sobretudo em sua saúde e sua qualidade de vida. A esta realidade atribui-se o nome de injustiça ambiental.

Desta forma o presente trabalho tem por objetivo principal determinar o papel da política frente a reparação da injustiça ambiental, a partir do conceito de Bem Viver estabelecido por Acosta (2016). Seu objetivo específico busca correlacionar o homem, a natureza e a política, demonstrando os laços sociais que os unem. Estabelecidos os objetivos que conduzem o desenvolvimento da pesquisa e compreendo a relevância desta problemática, 
como sendo uma condição que impacta profundamente a vida da sociedade brasileira, justifica-se o desenvolvimento deste trabalho.

A metodologia utilizada para a construção deste trabalho quanto aos seus objetivos, define-se como de cunho exploratório, pois busca evidenciar o problema e explicitá-lo. Em relação aos seus procedimentos técnicos, trata-se de uma pesquisa bibliográfica, a qual analisa e explora a temática, tendo por base o aporte principal de Acosta (2016) (GIL, 2OO8).

Este artigo se subdivide em três seções, a partir desta introdução. A primeira seção busca analisar a concepção do homem como parte da natureza, analisando a exploração do meio ambiente e sua relação com a política. A primeira seção ainda aborda e explica os termos justiça e injustiça ambiental, elencando seus impactos e mencionando os grupos mais afetados por estes problemas. A segunda seção pondera sobre o conceito de Bem Viver e seus princípios, e finaliza-se discorrendo sobre os impactos da interferência do homem sobre quatro principais parametrizações: territorial, temporal, social e ecológica. A última seção apresenta breves considerações finais sobre o tema.

\section{Observações: Homem x Natureza}

O que serve de parâmetro para analisar se o ser humano está interferindo na natureza quando este é parte integrante do meio?

Para responder a esta interrogação, necessário se faz observar toda uma contextualização sistêmica e generalista da questão, algo como "do geral ao particular", mas requer-se também um apanhado como "do particular ao geral", fazendo-se posteriormente um olhar analítico sobre as perspectivas Territorial, Temporal, Social e Ecológica. É lícito afirmar que, quase tudo, o que está ao "nosso redor" enquanto sociedade advém da natureza. A natureza é condição fundamental para o tecido social, isto é, da sobrevivência humana, seja em caráter individual, quanto plural, de espécie.

Grande parte das modificações ocorridas na natureza é realizada a partir da ação do ser humano, criando assim, relações de interdependência social, tais quais se podem citar: homem $\mathrm{x}$ homem, homem $\mathrm{x}$ natureza, e em especial natureza $\mathrm{x}$ homem $\mathrm{x}$ política. Todas as relações e interdependências sociais confrontam a convivência humana, pois o homem, o ser humano, como um ser social, necessita do outro, e o tecido social, a sociedade, cada indivíduo cumpre uma função, específica, por mais simples que esta seja, conquanto fundamental para a existência dessa relação dinâmica.

Pois bem, a relação homem $\mathrm{x}$ natureza $\mathrm{x}$ política é realizada em razão da dependência humana dos recursos que a natureza oferece, para que, com a força de trabalho 
do ser humano, a primeira natureza seja transformada em segunda. Entretanto, a relação de interdependência do trinômio homem x natureza x política, dá-se no elemento de motricidade, isto é, de influência que a política exerce, por ser a política que emana as diretrizes maiores de como será especificada e conduzida à relação de ação, sendo esta com equilíbrio, sustentabilidade e justiça ambiental, ou na ausência destes todos, podendo admitir-se numa questão da ausência, que haja uma relação consentida pela sociedade.

Porém toda essa evolução conduz a uma situação limite. A interferência do ser humano na natureza é indispensável para a continuidade do funcionamento da sociedade, mas por outro lado, é preciso destacar que, a natureza e seus recursos são finitos, isto é, esgotáveis e que necessita além do respeito, cuidados especiais, em função das consequências. Boff (1993. p. 11), aponta que:

[...] o ser humano individual e social é parte da natureza; ele pertence à natureza, bem como a natureza lhe pertence como cuidado e trabalho. [...] ele possui sua diferença específica na medida em que somente ele é um ser ético capaz de cuidar da natureza, potenciar sua dinâmica interna de ascensão, como e feri-la e até destruí-la.

Entre todo o ambiente e toda a natureza, o homem é o único ser que tem a capacidade de raciocínio para proteger o meio em que vive. Nesse sentido, é o único que consegue criar estratégias para que melhore sua própria qualidade de vida. É completamente paradoxal, inexplicável, mas por vezes é percebível que o ser humano esquece que faz parte da natureza. Santos, aponta que, o que chamamos hoje de agravo ao meio-ambiente, na verdade são agravos ao meio de vida do próprio homem (SANTOS, 1995. p. 697).

Neste sentido, para compreender toda essa circunstância e os delineamentos que esta percorre, é importante ter-se muito bem assimilado não apenas o conceito da justiça ambiental, mas sua decorrência maior, a "injustiça ambiental". Entende-se pela situação de Injustiça Ambiental a transferência oriunda das sociedades desiguais, de uma carga maior de danos ambientais originários de certo padrão de desenvolvimento para determinados grupos sociais de trabalhadores, preponderantemente de baixa renda, para populações especificamente de baixa renda, para grupos raciais discriminados e populações vulneráveis e marginalizadas (HERCULANO, 2002).

Considerado este entendimento, é possível afirmar que um meio ambiente, isto é, a natureza, saudável é um direito universal. Embora esteja sendo bastante difundida a ideia de que a crise ambiental, ou seja, o adoecimento da natureza seja global e generalizada, e estando 
toda a sociedade igualmente sujeita aos efeitos nocivos desta decorrência, os seus impactos não são democráticos.

Poluição e os riscos ambientais provocados por determinados segmentos industriais, tais como indústrias petrolíferas, mineradoras agronegócio etc. não atingem a sociedade de maneira uniforme. O modelo de desenvolvimento preponderante, infelizmente, é baseado no crescimento ilimitado e, portanto, no uso intensivo de recursos naturais, exigindo uma mecânica que somente se viabiliza na distribuição de forma desigual dos seus impactos negativos entre os grupos historicamente vulneráveis. Tais "agrupamentos" historicamente impactados continuam persistindo nas populações negras, indígenas, pobres e trabalhadoras que dispõem de carentes recursos políticos, financeiros e informativos para poderem se proteger. Podendo ser verificado em diversas situações conforme ilustração abaixo:

Figura 1-Flagrante de vulnerabilidade indígena no Brasil decorrente de intervenção humana.

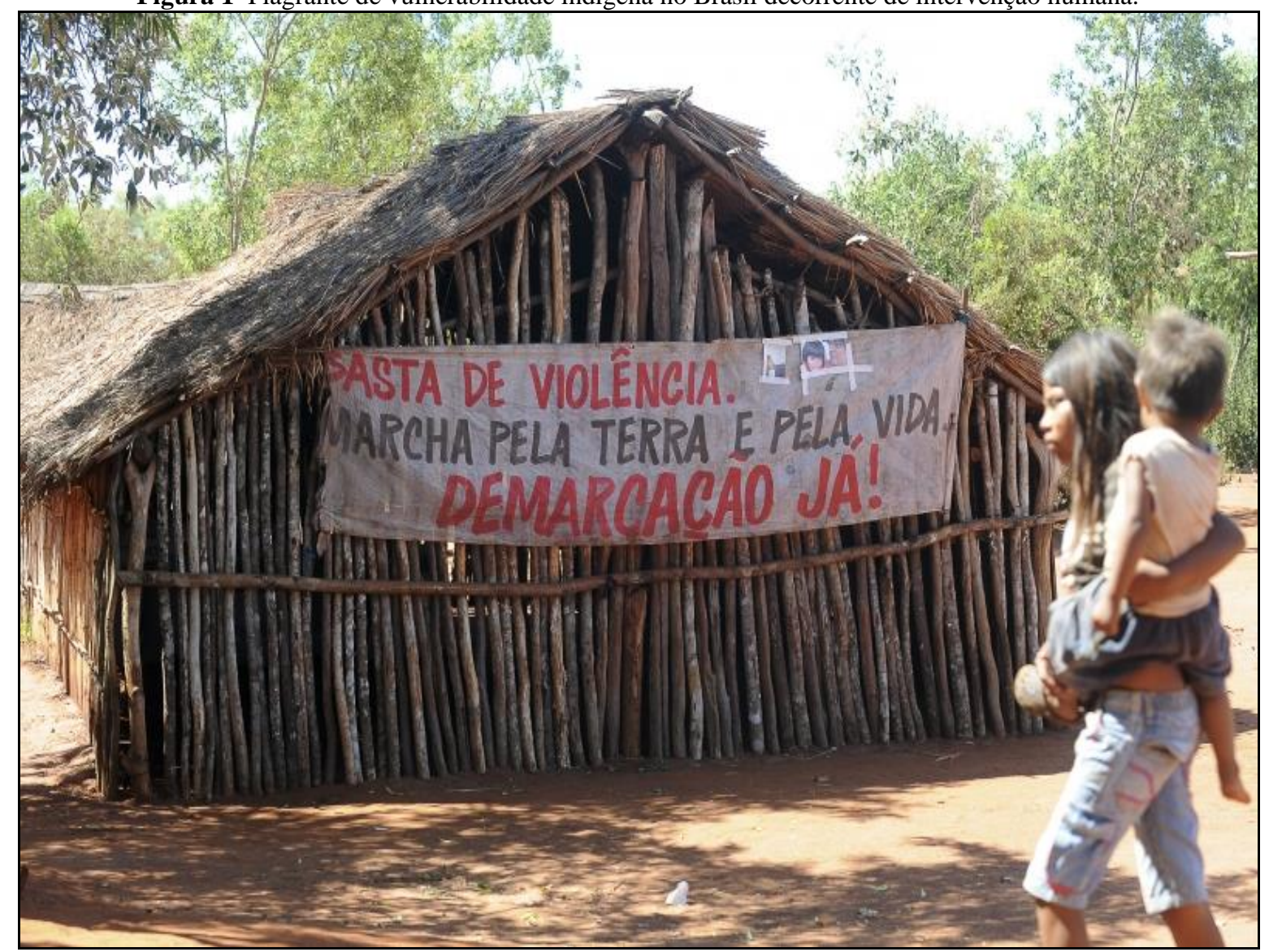

Fonte: Associated Press. Disponível: <https://www.ap.org/en-us/> Acesso em: 06 jul.2017

Habitualmente, verifica-se que é no território destes grupos sociais supracitados, que seguem sendo instalados majoritariamente tais empreendimentos mais impactantes, resultando não raro em perigo a sua saúde e aos seus modos de vida. Cabível considerar que 
esta realidade também provoca efeitos no campo, bem como nas cidades e nas grandes aglomerações urbanas, (DIAMOND, 2007).

Assim, a face da situação paradoxal, anteriormente mencionada e, dadas suas consequências, vem ganhando ênfase não somente como proposição corretiva ou alternativa, enfatizar da conceituação do "Bem Viver", proposta por Acosta (2016). Este, conecta pontos que, na visão de muitos autores, que por ele mesmo são citados, expõe o avanço de uma situação, que chega atualmente na deflagração de aguda desigualdade social, devastação ambiental e propriamente de crise econômica e crise política, vivida no mundo contemporâneo, inteiro. A escalada que deflagrou esta crise combinatória foi provocada por uma falta de equilíbrio e bom senso, no que fora um êxtase de desenvolvimento, originado pelo fim da Segunda Guerra Mundial, no Século 20, se produz num desencantamento por este mesmo status quo de desenvolvimento, tendo alcançado a atualidade.

Para Acosta (2016), o desenvolvimento ocidentalizou a vida no planeta. Segundo este autor o estabelecimento de determinados padrões de consumo já são considerados inconcebíveis, assim como as máquinas transformando os seres humanos em meras ferramentas, quando expõe que a relação deveria ser inversa, a chamada "eterna superioridade dos colonizadores", ao que se sentem legitimados em desqualificar conhecimentos, por exemplo, de povos tradicionais.

\section{O Bem Viver}

O "Bem Viver" de Acosta (2016), atenta para armadilhas, como o próprio coloca, de um "mercantilismo ambiental" exacerbado por várias décadas, que não contribuiu para melhorar a situação, mas sim, o inverso. Adentram conceitos de "economia verde", "desenvolvimento sustentável" etc. que conforme o autor, estes têm sido conceitos apenas para dar uma "maquiagem desimportante e distrativa", sendo que os indicadores ambientais e sociais, propostos por este conceitos que surgem em profusão, não conseguem chegar a um acordo e, que "acabam por cercear ideias inovadoras".

Requer atenção, que a base do pensamento do "Bem Viver" é indígena. Entre as muitas contribuições sobre o tema que foram aceitos pelos organizadores deste pensamento, há reflexões da comunidade Sarayaku, na província de Pastaza, no Equador, país onde se elaborou um "plano de vida", podendo-se chamar desta maneira, sintetizando os princípios fundamentais e norteadores do "Bem Viver" de Acosta (2016). Tal qual, está escrito no subtítulo da obra que formula o conceito, a proposição é mesmo ter que imaginar outros 
mundos possíveis, face ao agudar da injustiça ambiental presente no mundo contemporâneo, ocasionado pelo desequilíbrio no binômio, natureza x política, sendo o ser humano o gatilho.

Isso posto, Acosta (2016), propõe-se através do conceito do "Bem Viver", trazer a

luz uma reflexão qualitativa acerca de como possibilitar um equilíbrio entre a Natureza versus

Política, que além de não acarretar a deflagração de crises, conflitos e contenciosos, ajude ao ser humano compreender, que sua existência, realmente está interligada com a natureza, e não desconectada.

A espinha dorsal da proposição de Acosta (2016) por um equilíbrio dinâmico através do "Bem Viver", em um "Mundo Possível”, desenvolve-se através dos seguintes pontos:

1. Bem Viver, não é mais uma alternativa de ideia para o desenvolvimento dentro de uma extensa lista de opções, não. Apresenta-se mesmo como uma alternativa, diante a todas elas e fundamenta-se na construção de um estado plurinacional e eminentemente participativo.

2. Bem Viver, o convite é para se ter clareza, antes de tudo, sobre o que são os horizontes de um possível estado plurinacional. Através deste, propõe-se construir uma nova história, uma nova democracia, pensada, também sentida a partir do respeito aos povos originários, à diversidade e à natureza.

3. Bem Viver, tal como se propõe, a ser uma alternativa ao desenvolvimento, exige pois outra economia, sustentada em princípios de solidariedade e reciprocidade, responsabilidade, integralidade. Bem Viver, tem por objetivo construir um sistema econômico sobre bases comunitárias, orientadas por princípios diferentes dos que propagam tanto o capitalismo quanto o socialismo, demandando uma grande transformação, não apenas nos aparatos produtivos, mas também nos padrões de consumo, obtendo melhores resultados em termos de qualidade de vida. Requer uma lógica econômica que não se baseie na ampliação permanente do consumo em função da acumulação do capital, tendo haver que desmontar tanto a economia do crescimento como a sociedade do crescimento.

4. Bem Viver, requer que essa "nova economia" deva permitir a satisfação das necessidades atuais sem comprometer as possibilidades das gerações futuras, em condições que assegurem relações cada vez mais harmoniosas do ser humano consigo mesmo, e dos seres humanos entre os seus congêneres e propriamente com a natureza.

5. Bem Viver, estipula que os padrões de consumo devam focar para um prazo longo de sustentabilidade. Os seus valores irão encorajar novos padrões de consumo dentro dos limites ecológicos possíveis e aos quais todos poderão aspirar.

6. Bem Viver enxerga que descentralização assume um papel fundamental. O fundamento básico desta linha é o desenvolvimento das forças produtivas locais, do controle da acumulação e do "centramento" dos padrões de consumo.

7. Bem Viver, acima de tudo necessitade ser acompanhado de um processo político de participação plena, de maneira que se possam construir"contrapoderes" com níveis crescentes de influência no âmbito local.

8. Bem Viver, postula a ideia, em que não é fomentar uma "burguesia nacional" e sim voltar ao modelo de substituição de importações. O Mercado interno, dentro deste postulado, significa mercado de massas e, sobretudo, mercados comunitários onde predominará o "viver com o nosso e para os nossos", frisa Acosta (2016), ao qual vincula campo e cidade, rural e urbano. Só através disto, se poderá ser avaliado, a partir desse modelo, como se participar da economia mundial. 
9. Bem Viver, as necessidades humanas fundamentais poderão ser atendidas desde o início, como durante todo o processo de construção da proposição. A Sua realização não seria, então, a meta, mas sim o motor do processo.

10. Bem Viver, as pessoas e as comunidades poderão viver a construção de um processo autodependente e participativo. A lógica é que o "Bem viver" se converta em um bem público, com um grande poder integrador, tanto intelectual como político. Fortaleça processos de assembleias em espaços comunitários e, possibilite repensar profundamente os partidos e as organizações políticas tradicionais.

11. Bem Viver, o conceito fundamental é que um padrão de crescimento permanente é impossível. O Lema do Bem Viver é o "melhor com menos", expõe Acosta (2016). Logo se faz preferível se crescer pouco, mas crescer bem, a crescer muito, porém mal. Terá que haver um consenso e uma participação popular.

12. Bem Viver, o trabalho é um direito e um dever em uma sociedade que busca o "Bem Comum". Faz-se necessário pensar em um processo de redução do tempo de trabalho e da redistribuição do emprego.

13. Bem Viver, visualiza os seres humanos como uma promessa, não uma ameaça. Logo, não há que se esperar que o mundo se transforme para se avançar no campo da migração, há assim que agir para provocar essa mudança no mundo.

14. Bem Viver, surge com força, o tema dos bens comuns. Poderão ser sistemas naturais ou sociais, palpáveis ou intangíveis, distintos entre si, mas comuns, pois foram herdados ou construídos coletivamente. Nisto, é indispensável proteger as condições existentes para dispor dos bens comuns de forma direta, imediata e sem mediações mercantis. Terá que evitar a privatização dos bens comuns. Como isso, o que se busca é uma convivência sem miséria, sem discriminação, com um mínimo de coisas necessárias. O que se deverá combater será a excessiva concentração de riqueza, não a pobreza.

15. Por derradeiro, Bem Viver, não haverá que desenvolver a pessoas, pois será a pessoa que deverá se desenvolver. Para tanto, qualquer pessoa terá que ter as mesmas possibilidades de escolha, ainda que não detenha os mesmos meios.

Logo, possibilitada através da interpretação que partiu do enfoque geral para um específico, hora efetuada, consegue-se fixar-se parâmetro assertivo para se analisar o grau de interferência do ser humano na natureza, sendo este parte integrante, sim, do meio e, com isso prover melhor interpretação sobre diferentes perspectivas, que com firmeza, é possível verificar e afirmar:

a) Sob a parametrização de perspectiva territorial, o grau de interferência do ser humano na natureza, no mundo contemporâneo, registra-se tanto na extensão territorial sob a delimitação de um estado nacional quanto extensível para fora de suas fronteiras, em virtude da interferência humana na natureza, fazer transbordar para além de fronteiras os impactos e as consequências decorrentes. 
RELACult - Revista Latino-Americana de Estudos em Cultura e Sociedade

Revista Latinoamericana de Estudios en Cultura y Sociedad | Latin American Journal of Studies in Culture and Society V. 04, ed. especial, fev., 2018, artigo nº 682 | relacult.claec.org | e-ISSN: 2525-7870

Figura 2 - Linha de impacto de furacões de altíssima intensidadeAmérica do Norte, Caribe e Oceano Atlântico.

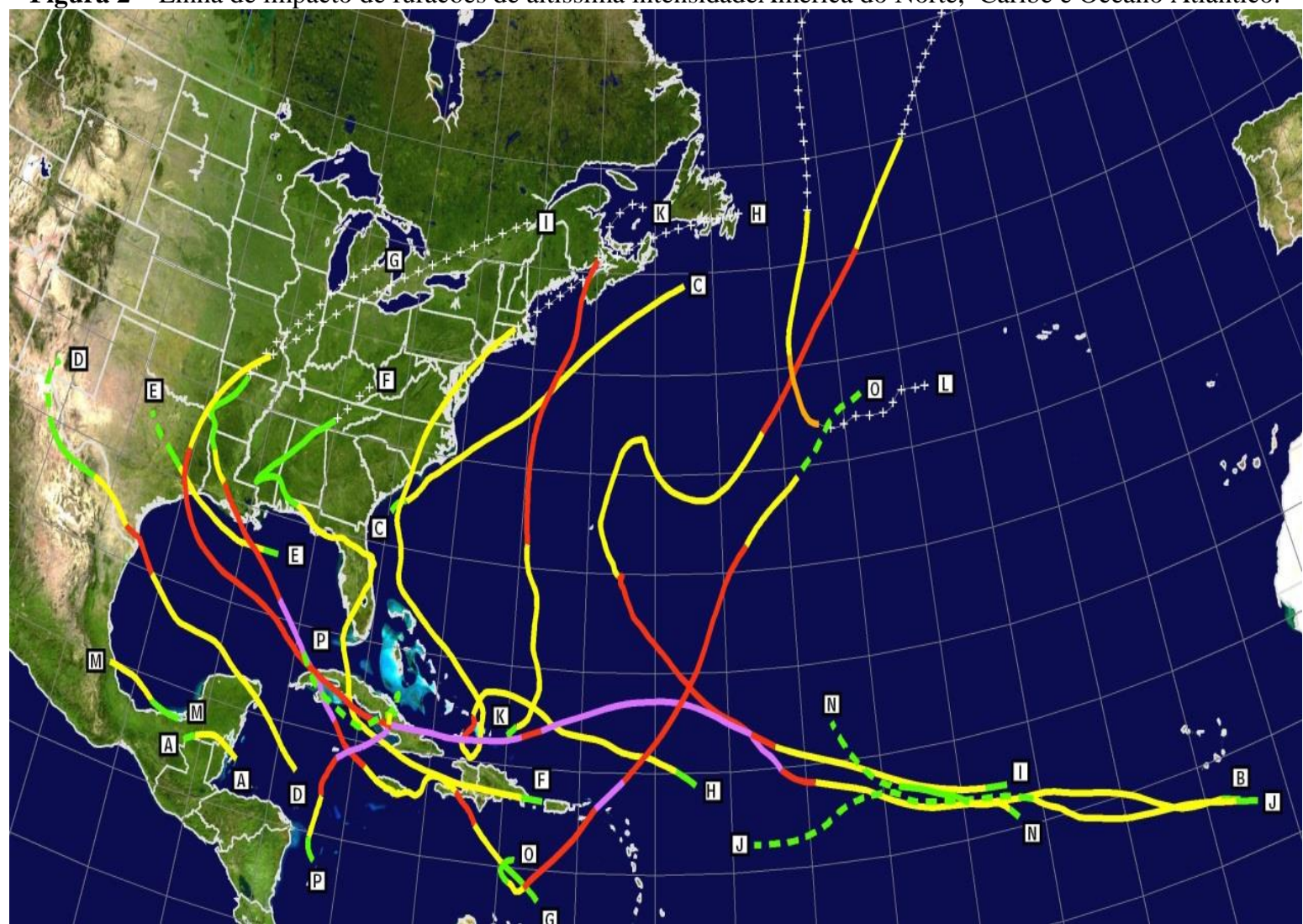

Fonte: NationalAeronauticsand Space Administration-NASA. Disponível em <www.nasa.gov> Acesso em: 06 jul. 2017

b) Sob a parametrização de perspectiva temporal, o grau de interferência do ser humano na natureza, no mundo contemporâneo, registra-se pela persistência, de sua ocorrência, não sendo assim uma lógica estanque, ao fato de o padrão de desenvolvimento adotado na maioria dos países, e em curso, provocar tal incidência, cuja tendência prevalece de evolução contínua. 
RELACult - Revista Latino-Americana de Estudos em Cultura e Sociedade

Revista Latinoamericana de Estudios en Cultura y Sociedad | Latin American Journal of Studies in Culture and Society V. 04, ed. especial, fev., 2018, artigo nº 682 | relacult.claec.org | e-ISSN: 2525-7870

Figura 3 - Evolução do impacto em McCartyGlacier, Alaska (USA).

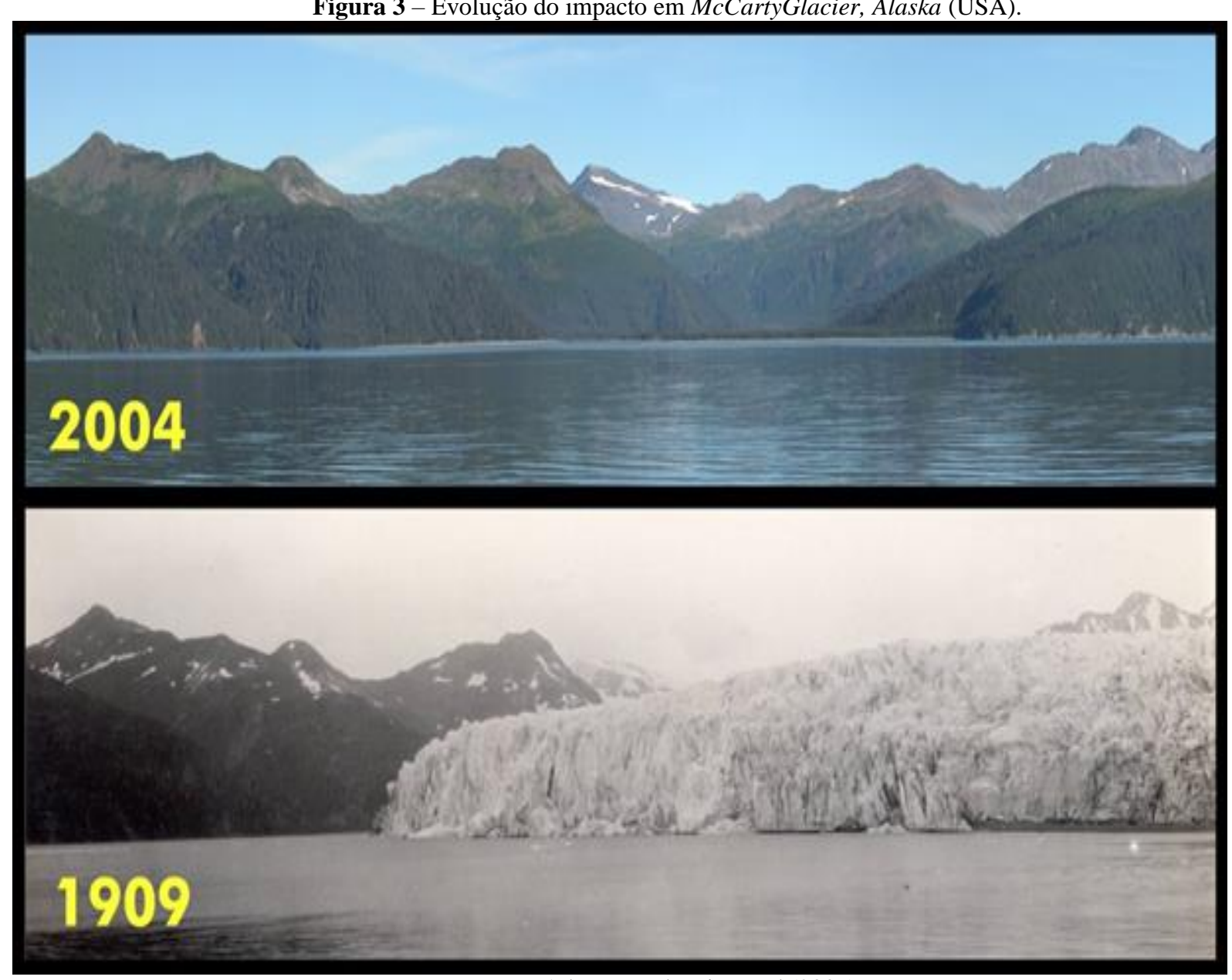

Fonte: Adaptação de Diamond (2007).

c) Sob a parametrização de perspectiva social, o grau de interferência do ser humano na natureza, no mundo contemporâneo, registra-se na ocorrência de erosão social, cujo reflexo são os desequilíbrios, conflitos, crises e expansão da pobreza e miséria artificialmente induzidas, ampliando fossos sociais, diametralmente opostos, conduzindo para uma separação na humanidade de ordem binária: os que têm, e os que não têm acessos, possibilidades, meios e recursos. 
Figura 4 - Flagrante de bolsão de pobreza no Brasil Contemporâneo.

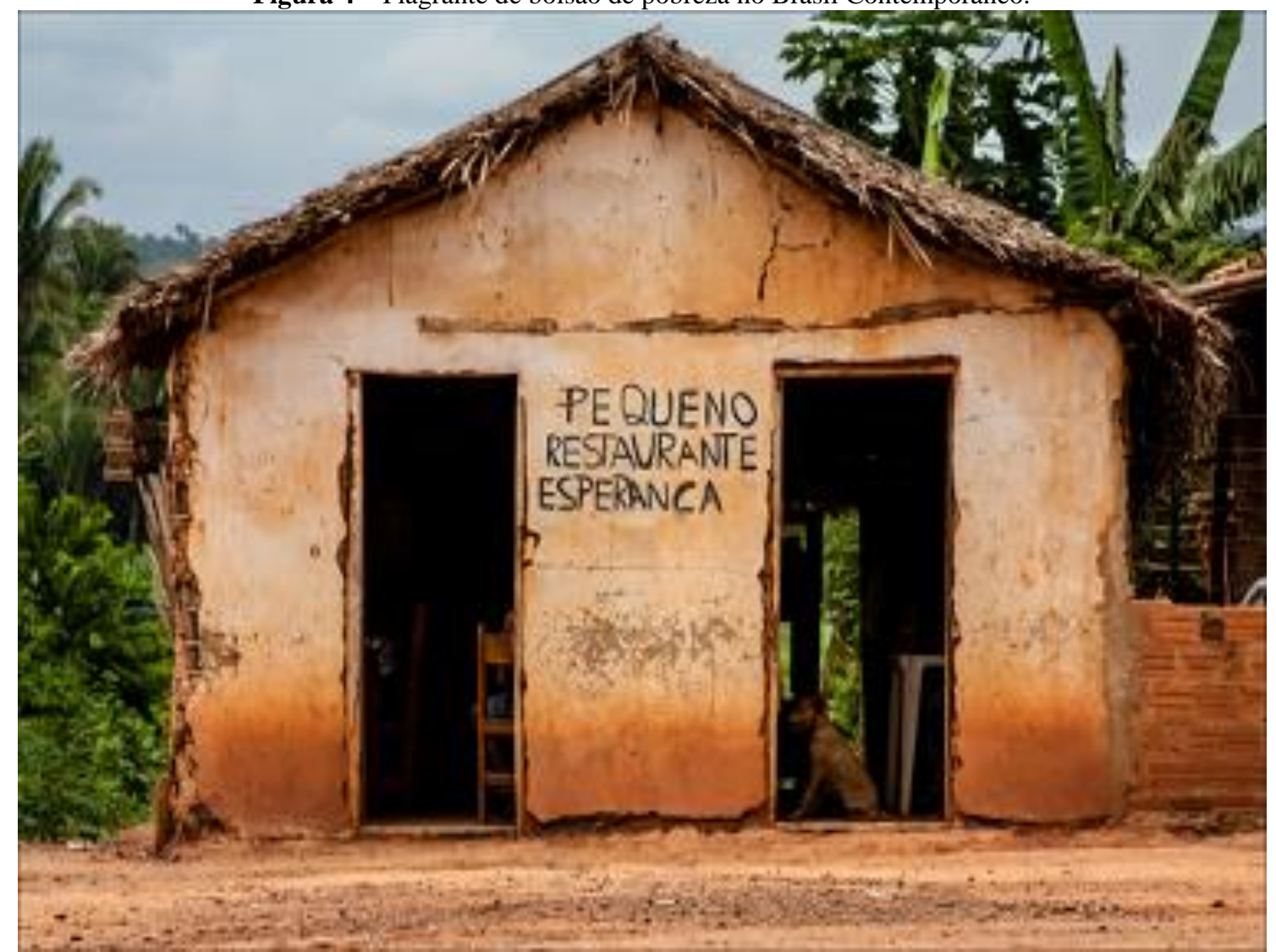

Fonte: Mundo Educação. Disponível em< http://mundoeducacao.bol.uol.com.br/geografia/a-pobreza-no-brasil.htm > Acesso em: 06 jul.2017.

d) Sob a parametrização de perspectiva ecológica, o grau de interferência do ser humano na natureza, no mundo contemporâneo, registra-se na ocorrência do esgarçamento dos limites daquilo que é considerado por natural, isto é, ao prevalecer uma lógica dominante irracional, paradoxal e irracional, de cunho constante, fixou-se o limite do naturalmente insuportável, configurado numa soma zero, simples cuja essência é: persistindo-se os padrões da lógica dominante em curso, a biosfera e a biodiversidade do planeta esgotar-se-ão todos os seus recursos, acarretando a extinção de qualquer possibilidade de vida humana; ou reconfigurando-se a lógica dominante em curso, por uma lógica mais equilibrada e equitativa, ainda é possível, num longo prazo, ainda aceitável, reverter os desdobramentos e os estragos gerados do passado e poder projetar ainda, uma possibilidade de vida humana no planeta, que não imprima à condição de xeque-mate à biosfera e a biodiversidade. 
Figura 5 - Capa da Revista Norte-Americana Time de 05 de abril de 2006.

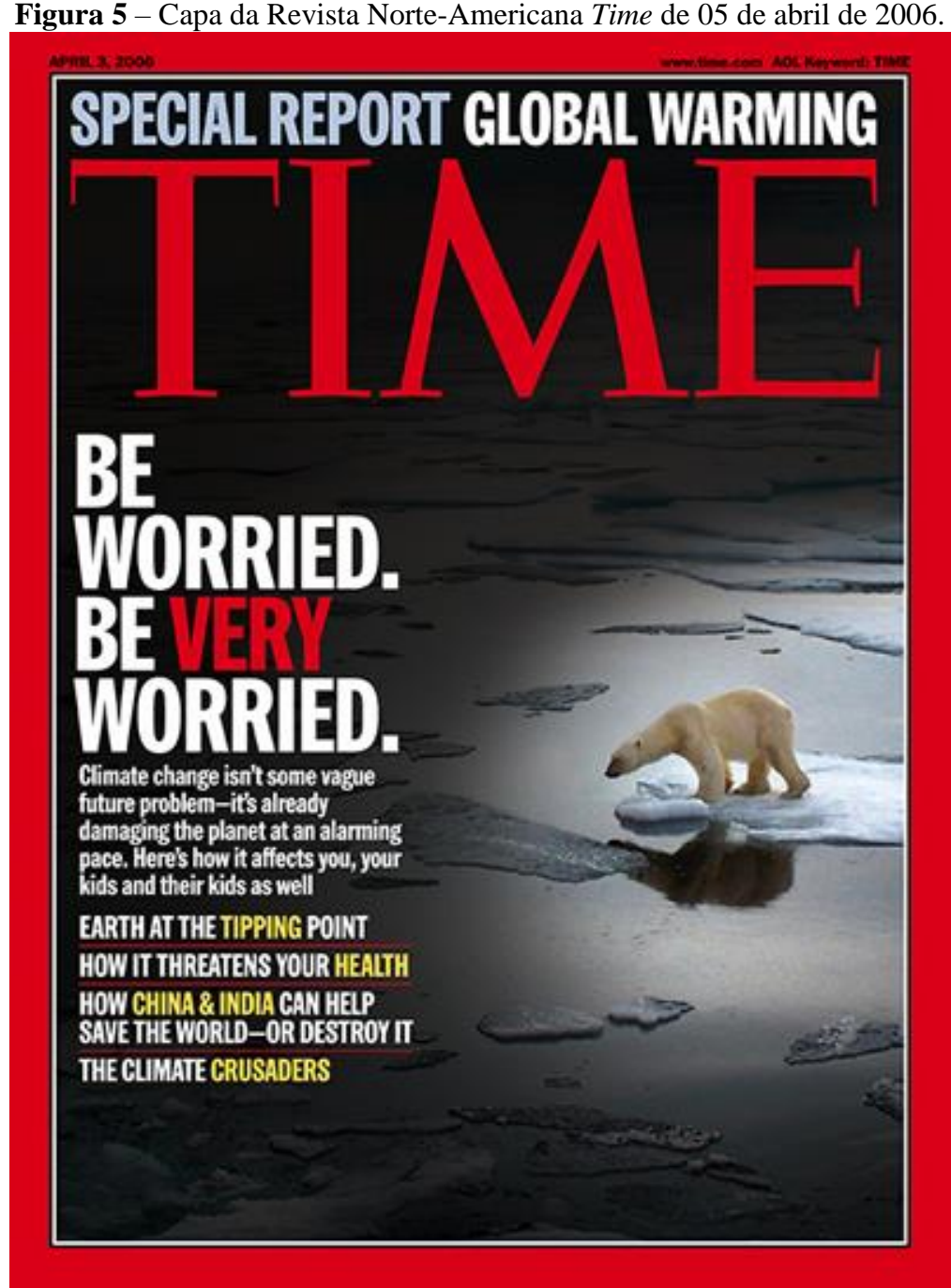

Fonte: Time Magazine. Disponível em:

<http://img.timeinc.net/time/magazine/archive/covers/2006/1101060403_400.jpg.> Acesso em: 06 jul.2017.

Ao passo, que não seja ficção, que observações e ponderações de inúmeros autores desta área científica, apontem para dados críveis e cientificamente comprovados, que tais interferências humanas na natureza, de fato, existam e, cuja relação entre a política e natureza constitui em correlações, pois que, entretanto, estão persistindo em sucessivos desequilíbrios, faz-se flagrante atentar, para sim, novos postulados, dinâmicos, de desenvolvimento, que equilibrem a relação homem, natureza e política, sem incorrer, em limites de ou possibilitar ou extinguir, sem alternativas, sua permanência enquanto raça, no planeta.

\section{Considerações Finais}

No decorrer do trabalho foram evidenciadas as relações sociais desenvolvidas pelo homem, das quais a relação política $\mathrm{x}$ natureza se destaca. Dentro desta análise emerge a percepção de que, gradativamente as condições ambientais estão se deteriorando, diante da 
constante exploração de seus recursos naturais. O contexto econômico atual, fortemente baseado no capitalismo e em seu consumismo exacerbado, interfere no modo de exploração da natureza, criando um impacto negativo que atinge as camadas menos favorecidas da sociedade, promovendo a injustiça social. Neste contexto, a política serve como instrumento possível para regulamentar e auxiliar o processo negativo de interferência humana no meio ambiente.

Durante o seu desenvolvimento foi apresentado o conceito de Bem Viver, cunhado por Acosta (2016), o qual apresenta pontos cruciais para encontrar um equilíbrio dinâmico para o contexto atual e, promovendo o que o autor chama de Mundo Possível. No Bem Viver, Acosta (2016) imagina um novo modelo econômico, mais consciente, regido por princípios de solidariedade e reciprocidade, como uma forma de reparação para a injustiça ambiental e seus impactos. Os resultados do estudo apresentam evidencias da interferência do ser humano na natureza, através de uma parametrização territorial, temporal, social e ecológica.

Conclui-se, portanto, que existem ações possíveis para recriar um "mundo possível", não uma sociedade utópica, plenamente livre das amarras e opressões historicamente formadas pelo sistema capitalista. Mas sim um lugar que amenize a exploração intensa dos recursos naturais do planeta reduzindo gradativamente o impacto da injustiça ambiental, que afeta os menos favorecidos.

\section{Referências}

ACOSTA, Alberto. O Bem Viver - Uma oportunidade para imaginar outros mundos. Tradução Tadeu Breta. São Paulo: Elefante Branco 2016.

BOFF, L. Ecologia, mundialização e espiritualização. Editora Ática. 1993.

DIAMOND, Jared. Colapso - Como as sociedades escolhem os fracassos ou o sucesso. Tradução Alexandre Raposo. Revisão Técnica Waldeck Dié Maia. 5 ed. Rio de Janeiro: Record, 2007.

GIL, Antonio Carlos. Como elaborar projetos de pesquisa. 4. ed. São Paulo: Atlas, 2008.

HERCULANO, S. Resenhando o debate sobre justiça ambiental: produção teórica, breve acervo de casos e a criação da rede brasileira de justiça ambiental. In: Revista Desenvolvimento e Meio Ambiente, nº 5, p. 143-149, jan/jun. 2002. Editora UFPR.

SANTOS, M. A questão do meio ambiente: desafios para a construção de uma perspectiva transdisciplinar. Anales de Geografía de La Universidad Complutense, n. 15, Servicio de Publicaciones. Universidad Complutense. Madrid, 1995. 